\title{
INFLUENCIA DE LA TEMPERATURA, PORCENTAJE DE GRASA Y SÓLIDOS NO GRASOS EN EL CRECIMIENTO CINÉTICO DE BACTERIAS ACIDOLÁCTICAS DEL YOGUR
}

\author{
INFLUENCE OF TEMPERATURE, PERCENTAGE OF FAT AND NONFAT \\ SOLIDS IN THE KINETIC GROWTH OF YOGURT LACTIC ACID BACTERIA
}

\author{
${ }^{1}$ Edwin Chila Choque; ${ }^{2}$ Thomas Ancco Vizcarra; ${ }^{3}$ Florentino Choquehuanca Cáceres
}

\begin{abstract}
RESUMEN
El estudio se realizó en la Universidad Nacional del Altiplano - Puno, ubicada a 3827 m.s.n.m. El objetivo fue determinar la influencia de la temperatura, porcentaje de grasa y sólidos no grasos en el crecimiento cinético de bacterias ácido lácticas del yogur (Lactobacillus delbrueckii subsp. bulgaricus y Streptococcus salivarius subsp. termophilus). Se planteó 12 tratamientos, estandarizándose los sólidos grasos (1\% y $3 \%$ ) y sólidos no grasos $\left(8 \%\right.$ y 9\%) incubado a $37^{\circ} \mathrm{C}, 40^{\circ} \mathrm{C}$ y $43^{\circ} \mathrm{C}$; determinando las $U F C / m l$, pH y acidez titulable. Obtenido la curva de crecimiento se ajustaron los parámetros cinéticos de crecimiento mediante el modelo matemático de Gompertz modificado; determinándose que el tiempo de adaptación ( $\lambda$ ) y la velocidad de crecimiento máximo ( $\mu_{\min }$ ) en Lactobacillus delbrueckii subsp. bulgaricus es influido por la temperatura. Asimismo, se determinó que el tiempo de generación ( $\mathrm{Tg})$ no es influido por la temperatura, porcentaje de grasa y sólidos no grasos. En tanto en el crecimiento de Streptococcus salivarius subsp. termophilus, la temperatura, porcentaje de grasa y sólidos no grasos no influyen en el tiempo de adaptación $(\lambda)$, tiempo de generación (Tg) y velocidad máxima de crecimiento $\left(\mu_{\operatorname{mad}}\right)$. Se determinaron valores de 4,6 a 4,8 en $\mathrm{pH}$, estadisticamente sin efecto en el yogurt; la acidez mostró mejor y mayor valor a temperatura de $37^{\circ} \mathrm{C}, 3 \%$ de grasa y $8 \%$ de sólidos no grasos determinándose $0,9 \%$ de ácido láctico.
\end{abstract}

Palabras Clave: Yogur, Lactobacillus delbruekii, Streptococcus salivarius, crecimiento cinético, Gompertz.

\section{ABSTRACT}

The study was developed at the National University of the Altiplano - Puno, located at 3827 over sea level. The objective was determine the influence of temperature, percentage of fat and nonfat solids in the kinetic growth lactic acid bacteria in yogurt (Lactobacillus delbrueckii subsp. Bulgaricus and Streptococcus salivarius subsp. Thermophilus). Twelve process were raised, standardizing the solid fats $(1 \%$ and $3 \%)$ and non-solid fats $\left(8 \%\right.$ and $9 \%$ incubated at $37^{\circ} \mathrm{C}, 40^{\circ} \mathrm{C}$ and $43{ }^{\circ} \mathrm{C}$; the $\mathrm{CFU} / \mathrm{ml}, \mathrm{pH}$ and titratable acidity were determined. The growth curve was obtained, the kinetic growth parameters were adjusted by the Modified Gompertz mathematical model; determined that the adaptation time $(\lambda)$ and the maximum growth rate $\left(\mu_{\operatorname{mid}}\right)$ in Lactobacillus delbrueckii subsp. bulgaricus is influenced by temperature, and the generation time (Tg) is not influenced by temperature, percentage of fat and non-solid fats. In the growth of Streptococcus salivarius subsp. thermophilus, temperature, percentage of fat and non-solid fat do not influence the adaptation time $(\lambda)$, generation time (Tg) and maximum growth rate $\left(\mu_{\operatorname{mid}}\right)$. Values of 4.6 to $4.8 \mathrm{in} \mathrm{pH}$, statistically without effect on yogurt; acidity showed a better and greater value at $37^{\circ} \mathrm{C}, 3 \%$ fat and $8 \%$ non-solid fats determined $0.9 \%$ of lactic acid.

Key Words: Yogurt, Lactobacillus delbruekii, Streptococcus salivarius, kinetic growth, Gompertz.

\section{INTRODUCCIÓN}

La leche es un producto fácilmente fermentable por la acción de las bacterias lácticas (acidificantes) dando lugar a un producto de aroma y sabor agradable que puede ser consumido. El yogurt es uno de los alimentos fermentados obtenido en forma natural, con las técnicas tradicionales de selección. A partir del desarrollo de la microbiologia, se aísla y selecciona algunas bacterias para ser utilizadas como cultivos iniciadores (Sánchez, 1992).

El cultivo láctico para yogur contiene bacterias acidolácticas (BAL), dentro de ellas el Lactobacillus delbrueckeil subsp. bulgaricus y el Streptococcus salivarius subsp. termopbilus, se encuentran en proporciones iguales (Gómez, 1999), que por efecto de su metabolismo le atribuyen diferentes sabores y textura, y contribuye a su valor nutricional. Ambas bacterias

Ingeniero Agroindustrial. Facultad de Ingenieria Agroindustrial de la Universidad Nacional del Altiplano. Puno-Perú.

'Magister en Poscosecha. Ingeniero Agroindustrial. Facultad de Ingenieria Agroindustrial de la Universidad Nacional José Maria Arguedas. Apurimac-Perui.

Ingeniero Agroindustrial. Facultad de Ingenieria Agroindustrial de la Universidad Nacional del Altiplano. Puno-Perú. 
tienen un crecimiento asociativo (simbiosis) que permite una producción rápida de ácido láctico. El Lactobacillus delbrueckii subsp. bulgaricus proporciona aminoácidos a partir del rompimiento de las proteínas de la leche, estimulando el crecimiento de Streptococcus salivarius subsp. termophilus, y éste a la vez produce ácido fórmico que estimula el crecimiento de Lactobacillus delbrueckii subsp. bulgaricus (Gómez, 1999).

$\mathrm{Al}$ inicio de la preparación, el $\mathrm{pH}$ y la acidez son favorables a los Streptococcus salivarius subsp. termopbilus, los que predominan y ponen en marcha la fermentación láctica (Espinoza y Zapata, 2010), por lo que la acidez es uno de los mejores indices de aceptabilidad de los consumidores, que junto al aroma van de la mano en los productos lácticos, por ello el interés en emplear bacterias simbióticas (Sánchez, 1992). La acidez en productos lácteos es expresada como porcentaje de ácido láctico, según Puhan (1986), que oscila entre 0,8 a $1,8 \%$ de ácido láctico. La formación de ácido láctico hasta alcanzar concentraciones más o menos superiores a las que determinan la coagulación, se controla en función al tipo de yogur. Este debe tener un mínimo de $0,7 \mathrm{~g}$ de ácido láctico por cada $100 \mathrm{~g}$ de yogur; por tanto, la determinación de acidez es un parámetro importante para su producción (Gómez, 1999).

Los valores de $\mathrm{pH}$ de un yogur están en un rango de 4,0 a 4,5 (Méndez, 2000), pero Meyer y Marcos (1982) mencionan que el $\mathrm{pH}$ de un yogur debe ser de 3,7 a 4,5 momento en el cual se produce el acetaldehído, sustancia que le confiere al yogur su sabor característico.

Asimismo, la temperatura determina la cinética de la acidificación e influye sobre los cambios de $\mathrm{pH}$ y otros que se producen como consecuencia de la presencia de oxigeno, de la concentración de otros componentes, de reacciones químicas y de cambios físicos (Skriver, 1997).

La temperatura debe elegirse próxima a la temperatura óptima de desarrollo del Streptococcus salivarius subsp. thermophilus, es decir, 42 a $45^{\circ} \mathrm{C}$, más que a una temperatura próxima a la óptima del Lactobacillus delbrueckii subsp. bulgaricus $\left(47\right.$ a $\left.50^{\circ} \mathrm{C}\right)$ ya que es preferible que los Streptococcus aseguren el comienzo de la fermentación láctica. Esta temperatura próxima de 42 a $45^{\circ} \mathrm{C}$ es, por otra parte, la temperatura simbiótica óptima (Luquet, 1991).

La actividad metabólica de los microorganismos del yogur está dada por la velocidad de crecimiento y el desarrollo de la acidez, de ahí la importancia de determinar y dar seguimiento a la acidez desarrollada durante la elaboración del yogur (Gómez, 1999). Las fases de crecimiento microbiano de mayor interés en alimentos corresponden a las tres primeras (adaptación, exponencial y estacionaria), ya que en ellas es donde ocurren los mayores problemas microbiológicos (producción de metabolitos importantes, cambios en las características de los alimentos, producción de toxinas, etc.). Tomando esas tres fases de la curva, el crecimiento presenta una forma sigmoidal, (Castro et al., 2008), para ajustar las curvas de crecimiento microbiano y encontrar los parámetros de la curva de crecimiento microbiano, se aplicó con mucho acierto la ecuación de Gompertz, que fue originalmente desarrollada para describir la mortalidad humana como una función de la edad. Gibson et al., (1987) el mismo que propuso el modelo modificado de Gompertz, fue considerado como el mejor modelo sigmoidal para curvas de crecimiento como lo demostraron Zwietering et al., (1990) McMeckin et al., (1993). Con la adopción de este modelo por el consorcio Food MicroModel en el Reino Unido y el grupo Pathogen Modelling Program (PMP) del USDA, el modelo es ampliamente usado en Microbiología la misma que se expresa en la ecuación:

$$
Y_{(t)}=A+C e^{\wedge}\left[-e^{\wedge}\{-B[t-M]\}\right]
$$

$\mathrm{Y}_{(0}=$ Conteo de la población al tiempo t (log10 población). $\mathrm{A}=$ Logaritmo de la población al tiempo $-\infty$, lo que equivale a la densidad de población al tiempo inicial $\left(\mathrm{Y}_{\min }=\mathrm{Y}_{0}\right)$.

$\mathrm{C}=$ Incremento final en el número de bacterias $\left(\log _{\mathrm{t}}\right)$, equivalente $\mathrm{Y}_{\operatorname{mix}}-\mathrm{Y}_{\min }$.

$\mathrm{M}=$ Tiempo en el cual el cultivo alcanza su máxima velocidad de crecimiento $(h)$

$\mathrm{B}=$ Velocidad máxima de crecimiento al tiempo $\mathrm{M}(1 / \mathrm{h})$, equivalente a la pendiente en el punto de inflexión.

$\mathrm{t}=$ tiempo $(\mathrm{h})$.

A partir de la ecuación anterior, pueden calcularse parámetros del crecimiento tales como: Fase de latencia, tiempo de generación, velocidad máxima de crecimiento.

\section{MATERIALES Y MÉTODOS}

Se empleó leche fresca y bacterias acidolácticas de Lactobacillus delbrueckii subsp. bulgaricus y Streptococcus salivarius subsp. termopbilus, YO-MIXTM 883 LYO 50 DCU; procedente de la empresa DANISCO. Los medios de cultivo utilizados fueron: M17 Agar para la siembra del Streptococcus salivarius subsp. termophilus, proveniente de la empresa OXOID de Inglaterra. MRS Agar para la siembra de Lactobacillus delbrueckii subsp. bulgaricus, proveniente de la empresa BRITANIA LAB de Argentina, y Lactosa Monohidratada proveniente de HMEDIA LAB de India.

La leche fue estandarizada a $1 \%$ y $3 \%$ de sólidos grasos y $8 \%$ y $9 \%$ de sólidos no grasos, se siguió la metodología de Alcázar (2002), seguidamente se pasteurizó a $85{ }^{\circ} \mathrm{C}$ por 30 minutos enfriándose rápidamente a temperaturas de 37,40 y $43^{\circ} \mathrm{C}$; a las que se adicionó $1 \%$ del cultivo mixto de yogur YOMIX 883 50DCU, extrayéndose $10 \mathrm{ml}$ de muestra para la siembra de bacterias acidolácticas; para el Streptococcus salivarius subsp. termophilus se sembraron por duplicado las diluciones bajas de $10^{4}$ y $10^{5}$; y para el Lactobacillus delbrueckit subsp. bulgaricus las diluciones de $10^{-2} \mathrm{y}$ $10^{3}$ respectivamente, realizándose recuentos a $0,30,60,180$ y 360 minutos tomándose muestras de $25 \mathrm{ml}$ y $9 \mathrm{ml}$ para determinar el pH y acidez.

\section{Preparación de muestras y diluciones}

Para la realización de los análisis microbiológicos, se utilizó la metodología propuesta por Montiel et al., (2010). Utilizando $10 \mathrm{~g}$ de muestra, que fueron diluidos en $90 \mathrm{ml}$ de una solución de agua peptonada al $0,1 \%$ estéril para el MRS Agar. Para el M17 Agar se siguió la metodología especificada en la ficha técnica del propio Agar. Posteriormente se realizó las diluciones decimales pertinentes, de las cuales se inoculó $1 \mathrm{~mL}$, en cajas Petri estériles ( $100 \mathrm{~mm} \times 15 \mathrm{~mm}$ ).

Las diluciones se prepararon a partir de la muestra 
Chila E. et al., Influencia de la Temperatura. Porcentaje de grasa y sólidos no grasos en el erecimiento cinético de bacterias acidolácticas del yogur

homogenizada, tomando de ella $1 \mathrm{ml}$ que se depositó en un tubo que contenía $9 \mathrm{ml}$ de agua de peptona estéril al $1 \%$. Después de agitado el tubo, se tomó $1 \mathrm{ml}$ que se añadió a un nuevo tubo con $9 \mathrm{ml}$ de agua de peptona estéril y así sucesivamente, hasta conseguir la dilución deseada.

\section{Cuantificación de Lactobacillus delbrueckii subsp. bulgaricus}

Se utilizó Agar MRS (De Man Rogosa Sharpe), el cual se disolvió en agua destilada desionizada, ajustando el $\mathrm{pH}$ a 5,4 , posteriormente se esterilizó a $121^{\circ} \mathrm{C}$ durante 15 $\mathrm{min}$. A las cajas Petri estériles se les adicionó de 15 a $20 \mathrm{ml}$ de medio de cultivo entre 40 y $45^{\circ} \mathrm{C}$, se dejó solidificar para luego hacer la siembra en superficie de las muestras $\left(10^{-2}\right.$ y 10 3 ) homogenizadas, luego se incubaron entre 35 y $37^{\circ} \mathrm{C}$, durante 72 horas. La cuantificación se realizó contando el número de unidades formadoras de colonias por mililitro (UFC/ml), con la ayuda de un contador de colonias.

\section{Cuantificación de Streptococcus salivarius subsp. termophilus} Se utilizó M17 Agar que se disolvió en agua destilada y se añadió en $10 \%$, solución estéril de lactosa, posteriormente se esterilizó a $121^{\circ} \mathrm{C}$ durante $15 \mathrm{~min}$. Para la muestra se extrajo $10 \pm 0,1 \mathrm{ml}$ de leche fermentada (yogur), para mezclarlo con la solución peptona al $0,1 \%$ estéril hasta que la muestra y el diluyente sean $50 \mathrm{ml}$ y previamente se realizó las diluciones sucesivas hasta $10^{-5}$. Después de la esterilización del medio de cultivo, éste se añadió de 14-15 $\mathrm{ml} \mathrm{a} 43 \pm 1^{\circ} \mathrm{C}$ en placas Petri, dejándolo solidificar para la siembra en superficie de las diluciones requeridas; luego las placas Petri se incubaron a $35^{\circ} \mathrm{C}$ durante 48 horas. La cuantificación se realizó contando el número de unidades formadoras de colonias por mililitro $(\mathrm{UFC} / \mathrm{ml}$ ), con la ayuda de un contador de colonias. Las colonias de Lactobacillus delbrueckii subsp. bulgaricus no crecieron, ni se desarrollaron, el crecimiento fue muy restringido.

\section{Método para el análisis fisicoquímico}

\section{Determinación de $p H$}

La medición del $\mathrm{pH}$ fue realizada a los $0,30,60,180$ y 360 minutos de incubación (proceso de fermentación) con un $\mathrm{pH}$-metro marca SevenGo ${ }^{\text {TM }}$ de METTLER TOLEDO. Se tomó $25 \mathrm{ml}$ de muestra, en un vaso de $50 \mathrm{ml}$, posteriormente se midió el $\mathrm{pH}$ por introducción directa del electrodo. Cada medición se realizó por triplicado.

\section{Determinación de acidez titulable}

La determinación de la acidez se realizó, para cada tratamiento en estudio, en todo el proceso de fermentación y formación del coágulo, en los tiempos de estudio establecidos por titulación con hidróxido de sodio de normalidad conocida $(\mathrm{N}=0,1)$, tomando una muestra de 9 $\mathrm{ml}$, y empleando como indicador la solución alcohólica de fenolftaleína a la concentración de $1 \%$; con la siguiente formula:

$\%$ Acido $=\{[(\mathrm{ml} \mathrm{NaOH})(\mathrm{N})(\mathrm{Meq})] /[$ Peso de la muestra $]\} * 100$

Dónde:

$\mathrm{ml} \mathrm{NaOH}$ : Gasto de $\mathrm{NaOH}$

$\mathrm{N}$ : Normalidad del $\mathrm{NaOH}$
Meq: Mili equivalente de ácido predominante en la muestra $(\mathrm{Meq}=90 / 1000=0,09)$

Determinación de la curva de creciniento y parametros de crecimiento cinético.

Los datos de crecimiento en Log UFC/ml y tiempo, fueron analizados en excel determinando los valores de los parámetros A, B, C y M, los que se ajustaron al modelo matemático de Gompertz planteado por Gibson et al., (1987) modificado con Software Curve Expert 1.4. El modelo utilizado queda expresado de la siguiente forma:

$$
\log \mathrm{N}=\mathrm{A}+\mathrm{C} \exp (-\exp (-\mathrm{B}(\mathrm{t}-\mathrm{M})))
$$

\section{Dónde:}

Log N: Es el logaritmo decimal $\left(\log _{10}\right)$ del número de microorganismos $(\mathrm{Log} \mathrm{UFC} / \mathrm{ml})$ al tiempo t.

A: Es el logaritmo decimal del número inicial de microorganismos $(\log \mathrm{UFC} / \mathrm{ml})$

C: Es el incremento en el logaritmo del número de microorganismos cuando el tiempo se incrementa indefinidamente $\left(\mathrm{N}^{\circ}\right.$ de ciclos de crecimiento) $(\mathrm{Log} \mathrm{UFC} / \mathrm{ml})$ $\mathrm{B}$ : Es la velocidad de crecimiento máxima relativa al tiempo $\mathrm{M}(\mathrm{Log} \mathrm{UFC} / \mathrm{ml} /$ hora $)$

M: Es el tiempo requerido para alcanzar la máxima velocidad de crecimiento (horas)

Los parámetros obtenidos a partir de la ecuación de Gompertz modificado permitieron calcular:

Velocidad máxima de crecimiento:

$\mu_{\max }=(\mathrm{BC} / \mathrm{e})(\log \mathrm{UFC} / \mathrm{ml}) /$ hora

Fase de latencia: $\lambda=M-(1 / B)$ (horas)

Tiempo de generación: $\mathrm{T}_{k}=\log 2(\mathrm{e} / \mathrm{BC})$ (horas)

\section{RESULTADOS Y DISCUSIÓN}

\subsection{Lactobacillus delbrueckeit subsp. bulgaricus}

\section{Efecto de la temperatura, porcentaje de grasa y sólidos no grasos sobre el tiempo de adaptación $(\lambda)$}

Los resultados del tiempo de adaptación del Lactobacillus delbrueckii subsp. bulgaricus están relacionados con el aumento de la temperatura, siendo evidente que cuanto más alta es la temperatura, menor es el tiempo que requiere para que se inicie su crecimiento logarítmico. Se ha determinado para $37^{\circ} \mathrm{C}$ un tiempo de adaptación de 1,113 horas $(66,78 \mathrm{~min})$, mientras que a $40^{\circ} \mathrm{C} 0,864$ horas $(51,84$ min) y a $43^{\circ} \mathrm{C}, 0,501$ horas $(30,06 \mathrm{~min})$. Estos resultados guardan relación a lo mencionado por Zarate (2009), donde el microorganismo se adapta a nuevo ambiente e inicia la actividad metabólica necesaria para utilizar de mejor forma los nutrientes disponibles como lo menciona Penfold (1914), citado por Robinson et al., (1998), y las células de Lactobacillus delbrueckii subsp. bulgaricus inician la multiplicación. (Montville, 2000).

En la Tabla $\mathrm{N}^{\circ} 01$ se presenta el análisis de varianza (ANOVA) donde se observa que existe una relación estadísticamente significativa $(\mathrm{p}<0,05)$ entre la variable independiente temperatura y el tiempo de adaptación $(\lambda)$, con un nivel de confianza del 95,0\%. El modelo de regresión múltiple fijado para describir la relación entre el 
Chila E. et al., Influencia de la Temperatura. Porcentaje de grasa y sólidos no grasos en el crecimiento cinético de bacterias acidolácticas del yogur

Tabla N01. Análisis de Varianza (ANOVA) para la regresión lineal múltiple sobre el tiempo de adaptación $(\lambda)$ del Lactobacillus delbrueckii subsp. bulgaricus.

\begin{tabular}{lcccccc}
\hline \multicolumn{1}{c}{ F. de V. } & G.L. & S.C. & C.M. & RAZÓN-F & VALOR-P & Significancia \\
\hline $\begin{array}{l}\text { Debido a la } \\
\text { regresión }\end{array}$ & 1 & 1,95229 & 1,95229 & 19,56 & 0,0013 & $*$ \\
$\begin{array}{l}\text { Error } \\
\text { Residual }\end{array}$ & 10 & 0,99834 & 0,099834 & & & \\
Total & 11 & 2,95063 & & & & \\
\hline
\end{tabular}

tiempo de adaptación ( $\lambda$ ) y la variable independiente temperatura, se expresó de la siguiente manera:

$$
\lambda=7,2875-0,164667 * \mathrm{~T}
$$

El coeficiente de determinación $\left(\mathrm{R}^{2}\right)$ indica que el modelo ajustado explica $66,16 \%$ de la variabilidad en el tiempo de adaptación ( $\lambda$ ). El coeficiente de determinación ajustada $\left(\mathrm{R}^{2}\right)$, que es más apropiada para comparar el modelo con diferente número de variables independientes, es $62,78 \%$. Cabe indicar que en este porcentaje el tiempo de adaptación es influido por la temperatura y un $37,21 \%$ es influido por otros factores diferentes al porcentaje de sólidos grasos y sólidos no grasos. No obstante, Buchanan y Cignarowicz (1990) mencionan que el tiempo de adaptación es influida por factores como el fenotipo de la bacteria, el tamaño del inóculo y por los cambios fisicoquímicos como la temperatura, $\mathrm{pH}$ y la disponibilidad de nutrientes.

Con el modelo determinado es posible predecir el tiempo de adaptación a temperaturas en el rango de $37^{\circ} \mathrm{C}$ a $43^{\circ} \mathrm{C}$ hasta un máximo de $44^{\circ} \mathrm{C}$ como lo menciona Gómez (1999).

Efecto de la temperatura, porcentaje de grasa y sólidos no grasos sobre el tiempo de generación $\left(T_{g}\right)$

E1 T5 reportó una $\mathrm{Tg}$ de 2,965 horas, probablemente debido a que la leche utilizada contenía una baja concentración de lactosa (Chervaux et al., 2000) los resultados mostraron para el Lactobacillus delbrweckii subsp. bulgaricus que el tiempo de generación $(\mathrm{Tg})$ aumenta de 68 min hasta $160 \mathrm{~min}$ (2,67 horas), cuando la concentración de lactosa varia de 0,4 a $0,1 \%$.

Los tratamientos T2, T4, T6, T7, T8, T10 y T11 reportaron tiempos de generación menores a 0,921 horas (55 min), estos menores tiempos de generación pueden estar atribuidos al incremento del pH Agatangelo (2007).

El tiempo de generación para T1, T3 Y T9, fue de 1,1 horas, valor similar al determinado por Agudelo et al., (2010) en medio de fermentación con almidón, mientras que otros autores reportaron un tiempo de generación $(\mathrm{Tg})$ de 1,98 horas para el Lactobacillus delbrueckii subsp. bulgaricus.

En la Tabla $\mathrm{N}^{\circ} 02$ se observa que no existe una relación estadísticamente significativa $(\mathrm{p} \geq 0,05)$ entre temperatura, porcentaje de grasa y sólidos no grasos, con un nivel de confianza del $95,0 \%$, sobre el tiempo de generación del Lactobacillus delbrueckii subsp. Bulgaricus, efecto que probablemente se deba a la acción metabólica, disponibilidad de nutrientes y factores ambientales como lo menciona Bhunia y Ray (2010).
Tabla $\mathbf{N}^{\circ} 02$. Análisis de Varianza (ANOVA) para la regresión lineal múltiple sobre el tiempo de generación ( $\mathrm{Tg})$ del Lactobacillus delbrueckii subsp. bulgaricus.

\begin{tabular}{lcccccc}
\hline \multicolumn{1}{c}{ F. de V. } & G.L. & S.C. & C.M. & RAZÓN-F & VALOR-P & Significancia \\
\hline $\begin{array}{l}\text { Debido a la } \\
\text { regresión }\end{array}$ & 3 & 2,81581 & 0,938605 & 2,04 & 0,1873 & n.s. \\
$\begin{array}{l}\text { Error } \\
\text { Residual }\end{array}$ & 8 & 3,68591 & 0,460739 & & & \\
Total & 11 & 6,50172 & & & & \\
\hline
\end{tabular}

Efecto de la temperatura, porcentaje de grasa y sólidos no grasos sobre la máxima velocidad de crecimiento $\left(\mu_{\text {mix }}\right)$

En la Tabla $\mathrm{N}^{\circ} 03$ se muestra el análisis de varianza (ANOVA) para la máxima velocidad de crecimiento $\left(\mu_{\min }\right)$ en el que se determina que existe una relación significativa $(\mathrm{p}<0,05)$ con la temperatura. Se estableció el modelo de la siguiente forma:

$$
\mu_{\text {max }}=-5,64633+0,159875^{*} \mathrm{~T}
$$

Tabla $\mathbf{N}^{\circ} 03$. Análisis de Varianza (ANOVA) para la regresión lineal múltiple sobre la velocidad máxima de crecimiento $\left(\mu_{\text {max }}\right)$ del L actobacillus delbrueckii subsp. bulgaricus.

\begin{tabular}{lcccccc}
\hline \multicolumn{1}{c}{ F. de V. } & G.L. & S.C. & C.M. & RAZÓN-F & VALOR-P & Significancia \\
\hline $\begin{array}{l}\text { Debido a la } \\
\text { regresión }\end{array}$ & 1 & 1,84032 & 1,84032 & 5,61 & 0,0394 & $*$ \\
$\begin{array}{l}\text { Error } \\
\text { Residual }\end{array}$ & 10 & 3,27944 & 0,327944 & & & \\
Total & 11 & 5,11976 & & & \\
\hline
\end{tabular}

Este efecto significativo de la temperatura demuestra la variación de los resultados obtenidos, donde se observan que a temperatura de $37^{\circ} \mathrm{C}$ se alcanzó una $\mu_{\text {mix }}$ de $0,401 \mathrm{Log} \mathrm{UFC} / \mathrm{ml} /$ hora, para $40^{\circ} \mathrm{C}$ una $\mu_{\text {max }}$ de $0,486 \mathrm{Log}$ $\mathrm{UFC} / \mathrm{ml} /$ hora y para $43^{\circ} \mathrm{C} \mu_{\operatorname{mix}}$ de $1,360 \mathrm{Log} \mathrm{UFC} / \mathrm{ml} /$ hora en promedio.

Los tratamientos $\mathrm{T} 2$ y $\mathrm{T} 7$ reportaron valores de 0,707 y 0,593 Log UFC/ml/hora, variación debida a las características de crecimiento del Lactobacillus delbrueckit subsp. bulgaricus, las fuentes de carbono, como lo menciona Chervaux et al., (2000), y a las concentraciones de lactosa, ya que por debajo de $0,4 \%$ limitan el crecimiento del Lactobacillus delbrueckii subsp. bulgaricus, porque la lactosa como medio es más rápido que en glucosa, manosa y fructosa.

Los tratamientos $\mathrm{T} 10, \mathrm{~T} 11$ y $\mathrm{T} 12$ reportaron valores de 1,146 $\mathrm{Log} \mathrm{UFC} / \mathrm{ml} /$ hora, 1,615 Log $\mathrm{UFC} / \mathrm{ml} /$ hora y $2,408 \mathrm{Log} \mathrm{UFC} / \mathrm{ml} /$ hora, las altas velocidades de crecimiento fueron afectadas por la temperatura, $\mathrm{pH}$ y la concentración del substrato Agudelo et al., (2010), asociado a la simbiosis Veringa, Galesloot y Davelaar (1968); Bottazi, Battistotti y Vescovo(1971), citado por Tamime y Robinson (1991) y Gómez (1999), conducta que es estimulada por la producción de ácido fórmico por el Streptococcus salivarius subsp. termophilus durante la incubación aumentando su velocidad de crecimiento, así como la generación de ácido pirúvico y el dióxido de carbono, Tamime y Robinson (1991). 


\subsection{Streptococcus salivarius subsp. termopbilus}

Efecto de la temperatura, porcentaje de grasa y sólidos no grasos sobre el tiempo de adaptación $(\lambda)$

La Tabla $\mathrm{N}^{\circ} 04$ muestra que no existe una relación estadísticamente significativa $(\mathrm{p} \geq 0,05)$ entre temperatura, porcentaje de grasa y sólidos no grasos, grasos sobre el tiempo de adaptación $(\lambda)$, con un un tiempo de adaptación para los tratamientos T2, T5, T10, T12 de 0,6 horas (36 min); 0,9 horas $(54 \mathrm{~min})$ para $\mathrm{T} 7 \mathrm{y} \mathrm{T} 8 ; 1,684 ; 1,229$ y 1,4 horas para T1, T3 y T4 y 0,148 horas ( $8,88 \mathrm{~min})$ para T9. Resultados que muy posiblemente sean debidos a los rangos de temperatura de estudio que fueron menores a $37^{\circ} \mathrm{C}$ como lo menciona Aguilar (2008), que determinó para el Streptococcus salivarius subsp. termophilus 37 y $40^{\circ} \mathrm{C}$. Sin embargo, Gómez (1999) sostiene que la temperatura óptima de crecimiento y desarrollo del Streptococcus salivarius subsp. termophilus está entre 40 y $45^{\circ} \mathrm{C}$. No obstante Courtin et al., (2002) determinó $42^{\circ} \mathrm{C}$, encontrando un tiempo de adaptación de 60 a 90 minutos.

Tabla N04. Análisis de Varianza (ANOVA) para la regresión lineal múltiple sobre el tiempo de adaptación $(\lambda)$ Streptococcus salivarius subsp. termophilus.

\begin{tabular}{lcccccc}
\hline \multicolumn{1}{c}{ F. de V. } & G.L. & S.C. & C.M. & RAZÓN-F & VALOR-P & Significancia \\
\hline $\begin{array}{l}\text { Debido a la } \\
\text { regresión }\end{array}$ & 3 & 1,85151 & 0,61717 & 2,69 & 0,1166 & n.s. \\
$\begin{array}{l}\text { Error } \\
\text { Residual }\end{array}$ & 8 & 1,83206 & 0,229007 & & & \\
Total & 11 & 3,68357 & & & & \\
\hline
\end{tabular}

Efecto de la temperatura, porcentaje de grasa y sólidos no grasos sobre el tiempo de generación $\left(\mathrm{T}_{\mathrm{g}}\right)$

El tiempo de generación no presentó diferencias significativas por efecto de la temperatura, porcentaje de grasa y sólidos no grasos como se observa en la Tabla $\mathrm{N}^{\circ} 05$ El tiempo de generación del Streptococcus salivarius subsp. termophilus para T1 fue de 1,354 horas, mientras que para T2, T5, T8, fue de 0,3 horas ( $18 \mathrm{~min})$, para T6 y T 7 fue de 0,5 ( 30 $\mathrm{min}$ ) horas, para T4 y T9 fue de 0,4 (24min) horas, para T11 y T12 fue de 0,1 horas ( $6 \mathrm{~min})$, estos tiempos de generación cortos posiblemente indicarian las condiciones óptimas de crecimiento; y para T3 se determinó 2,398 horas. Por lo que se infiere que el tiempo de generación esté probablemente asociado a las inherentes propiedades fisiológicas del Streptococcus salivarius subsp. termophilus y factor ambiental asi como, la velocidad de aireación, como lo indica Yousef y Carlstrom (2006).

Tabla $\mathbf{N}^{\circ} 05$. Análisis de Varianza (ANOVA) para la regresión lineal múltiple para el tiempo de generación $(\mathrm{Tg})$ del Streptococcus salivarius subsp. termophilus.

\begin{tabular}{lcccccc}
\hline \multicolumn{1}{c}{ F.de V. } & G.L. & S.C. & C.M. & RAZÓN-F & VALOR-P & Significancia \\
\hline $\begin{array}{l}\text { Debido a la } \\
\text { regresión }\end{array}$ & 3 & 2,2552 & 0,751734 & 2,60 & 0,1244 & n.s. \\
$\begin{array}{l}\text { Error } \\
\text { Residual }\end{array}$ & 8 & 2,31237 & 0,289046 & & & \\
Total & 11 & 4,56757 & & & & \\
\hline
\end{tabular}

Efecto de la temperatura, porcentaje de grasa y sólidos no grasos sobre máxima velocidad de crecimiento $\left(\mu_{\text {max }}\right)$

La velocidad máxima de crecimiento no presentó efecto alguno por efecto de la temperatura, porcentaje de grasa y sólidos no grasos sobre máxima velocidad de crecimiento $\left(\mu_{\max }\right)$; en T1 y T3 se determinó $\mu_{\max }$ de 0,222 y 0,126 Log UFC/ml/hora, en T2, T3, T4, T5, T6, T7, T8, T9 y $\mathrm{T} 10 \mu_{\operatorname{mix}}$ entre 0,5 a $0,9 \mathrm{Log} \mathrm{UFC} / \mathrm{ml} /$ hora, mientras que T11 y T12 $\mu_{\operatorname{mix}}$ de 2,284 y 2,568 Log UFC/ml/hora, estos dos valores están muy relacionados al tiempo de generación y afirmamos que T11 y T12 del crecimiento del Streptococcus salivarius subsp. termophilus es el más adecuado.

Tabla N06. Análisis de Varianza (ANOVA) para la regresión lineal múltiple sobre la velocidad máxima de crecimiento $\left(\mu_{\text {mix }}\right)$ del Streptococcus salivarius subsp. termophilus.

\begin{tabular}{lcccccc}
\hline \multicolumn{1}{c}{ F.de V. } & G.L. & S.C. & C.M. & RAZÓN-F & VALOR-P & Significancia \\
\hline $\begin{array}{l}\text { Debido a la } \\
\text { regresión }\end{array}$ & 3 & 3,46392 & 1,15464 & 3,49 & 0,0698 & n.S. \\
$\begin{array}{l}\text { Error } \\
\text { Residual }\end{array}$ & 8 & 2,64445 & 0,330557 & & & \\
Total & 11 & 6,10838 & & & & \\
\hline
\end{tabular}

Gómez (1999) sostiene que la velocidad máxima de crecimiento del Streptococcus salivarius subsp. termophilus a inicios de la fermentación es mayor que la del Lactobacillus delbrueckii subsp. bulgaricus, posiblemente se deba a lo afirmado por Courtin et al., (2002) quien indica que la disposición de nutrientes suministrados por el medio estimulan el crecimiento rápido del Streptococcus salivarius subsp. termophilus. Este mismo autor investigó el crecimiento del Streptococcus salivarius subsp. termophilus en leche descremada incubada a $42^{\circ} \mathrm{C}$, y en caldo M17, llegando a obtener $\mu_{\operatorname{mix}}$ de 0,85 a $0,89 \mathrm{Log} \mathrm{UFC} / \mathrm{ml} /$ hora, en el estudio se determinó en T7 ( $\mu_{\text {mix }}=0,892 \mathrm{Log} \mathrm{UFC} / \mathrm{ml} /$ hora) valor similar al determinado por Courtin et al., (2002), donde se observa también la asociación al efecto de simbiosis como lo menciona Gómez (1999) y Bautista, Dahiya y Speck (1966), citado por Tamime y Robinson (1991). Se liberan aminoácidos esenciales como la valina, histidina y glicina de la caseína. Para Tamime y Robinson (1991) otro factor atribuido al crecimiento del Streptococcus salivarius subsp. termopbilus es la variación de la composición química de la leche durante el año, por tanto la leche puede ser deficitaria en algunos aminoácidos, y sugieren que durante la primavera el Streptococcus salivarius subsp. termopbilus requiere aminoácidos como: leucina, lisina, cisteína, acido aspártico, histidina y valina, y durante el otoño e invierno los aminoácidos requeridos son: glicina, isoleucina, tirosina, ácido glutámico y metionina.

3.3. Determinación de la temperatura, porcentaje de grasa y sólidos no grasos que presentan mejores valores fisicoquímicos en el proceso de incubación de las bacterias acido lácticas

\section{Determinación de $\mathrm{pH}$}

El proceso de fermentación de la leche durante la incubación, comprendida entre las 0 a 360 minutos se 
Chila E. et al., Influencia de la Temperatura, Porcentaje de grasa y sỏlidos no grasos en el crecimiento cinético de bacterias acidolácticas del yogur

presenta en la Figura $\mathrm{N}^{\circ} 01$; se observa un descenso del $\mathrm{pH}$ en los 12 tratamientos a temperaturas de $37^{\circ} \mathrm{C}, 40^{\circ} \mathrm{C}$ y $43^{\circ} \mathrm{C}$, con porcentajes de 1 y $3 \%$ de grasa y 8 y $9 \%$ de sólidos no grasos, el $\mathrm{pH}$ desciende por acción de la fermentación de la lactosa, por bacterias acidolácticas (Lactobacillus delbrueckii subsp. bulgaricus y Streptococcus salivarius subsp. termophilus), Amiot (1991), Gómez (1999) y Díaz et al., (2004); el descenso del $\mathrm{pH}$ desestabiliza las micelas de caseína suspendidas en la fase acuosa de la leche (Belaunzarán, 2010), y a pH 6,6, una molécula de proteína con carga neta negativa. Estas permanecen separadas debido a que poseen la misma carga y se repelen entre sí, al añadirse iones hidrógeno, son absorbidos por las moléculas de proteínas a cierto $\mathrm{pH}$ donde la carga neta de las proteínas es cero, y las moléculas ya no se repelen entre sí, produciendo la desestabilización de las mismas alcanzando el punto isoeléctrico de la proteína.

$\mathrm{El}$ análisis de varianza mostrado en la Tabla $\mathrm{N}^{\circ} 07$ muestra que ninguno de los factores e interacciones tiene un efecto significativo $(\mathrm{p}>0,05)$ sobre el $\mathrm{pH}$ con un $95,0 \%$ de confianza para los 12 tratamientos durante el proceso de fermentación.

Los valores de $\mathrm{pH}$ obtenidos en los 12 tratamientos están entre 4,5 y 4,8, estos valores se encuentran dentro del límite citado por Meyer y Marcos (1982) y Méndez (2000), que afirman que el $\mathrm{pH}$ de un yogur debe ser de 3,7 a 4,5 y de 4 a 4,5 ; momento en el cual se produce el acetaldehído, sustancia que le confiere al yogur su sabor característico.

Así mismo Hardi y Slacanac (2000) mencionan que la disminución de $\mathrm{pH}$ en productos lácteos fermentados es influida por la proporción de grasa de la leche y el cultivo iniciador. Por tanto los valores de $\mathrm{pH}$ de 4,5 a 4,8, obtenidos en la presente investigación coinciden con los resultados reportados por Hernández (2004).
Tabla $\mathrm{N}^{\circ} 07$. Análisis de varianza (ANOVA) para la variación de $\mathrm{pH}$.

\begin{tabular}{lccccc}
\hline \multicolumn{1}{c}{ F. de V. } & GL & SC & CM & Fc & Significancia \\
\hline A:Temperatura & 2 & 0,0783167 & 0,0391583 & 1,14 & n.s. \\
B:Grasa & 1 & 0,081225 & 0,081225 & 2,36 & n.s. \\
C:Sólidos no Grasos & 1 & 0,00173611 & 0,00173611 & 0,05 & n.s. \\
INTERACCIONES & & & & & \\
AB & 2 & 0,0508167 & 0,0254083 & 0,74 & n.s. \\
AC & 2 & 0,0388722 & 0,0194361 & 0,56 & n.s. \\
BC & 1 & 0,00513611 & 0,00513611 & 0,15 & n.s. \\
ABC & 2 & 0,0977722 & 0,0488861 & 1,42 & n.s. \\
Error Exp. & 24 & 0,8264 & 0,0344333 & & \\
TOTAL & 35 & 1,18027 & & & \\
\hline
\end{tabular}

\section{Determinación de acidez}

La acidez desarrollada en los 12 tratamientos aumenta de forma exponencial (Figura $\mathrm{N}^{\circ} 02$ ) entre las 0 a 6 horas (360 minutos), Alcázar (1999) y Díaz et al., (2004) mencionan que el incremento se debe a la acción del Lactobacillus delbrueckii subsp. bulgaricus y Streptococcus salivarius subsp. termophilus sobre la lactosa. Los 12 tratamientos estudiados reportaron valores entre 0,7 a 0,9 . Esto valores se encuentran dentro de lo indicado por Puhan (1986) que es 0,8 a 1,8 .

El porcentaje de ácido láctico en los tratamientos probablemente se deba al desarrollo rápido del Streptococcus salivarius subsp. termophilus al inicio de la fermentación, que posibilita el inicio de la producción de ácido láctico, pero luego el Streptococcus salivarius subsp. termophilus es inhibido por efecto del ácido láctico y la producción de ácido láctico es continuada por el Lactobacillus delbrueckii subsp. Bulgaricus Gómez (1999).

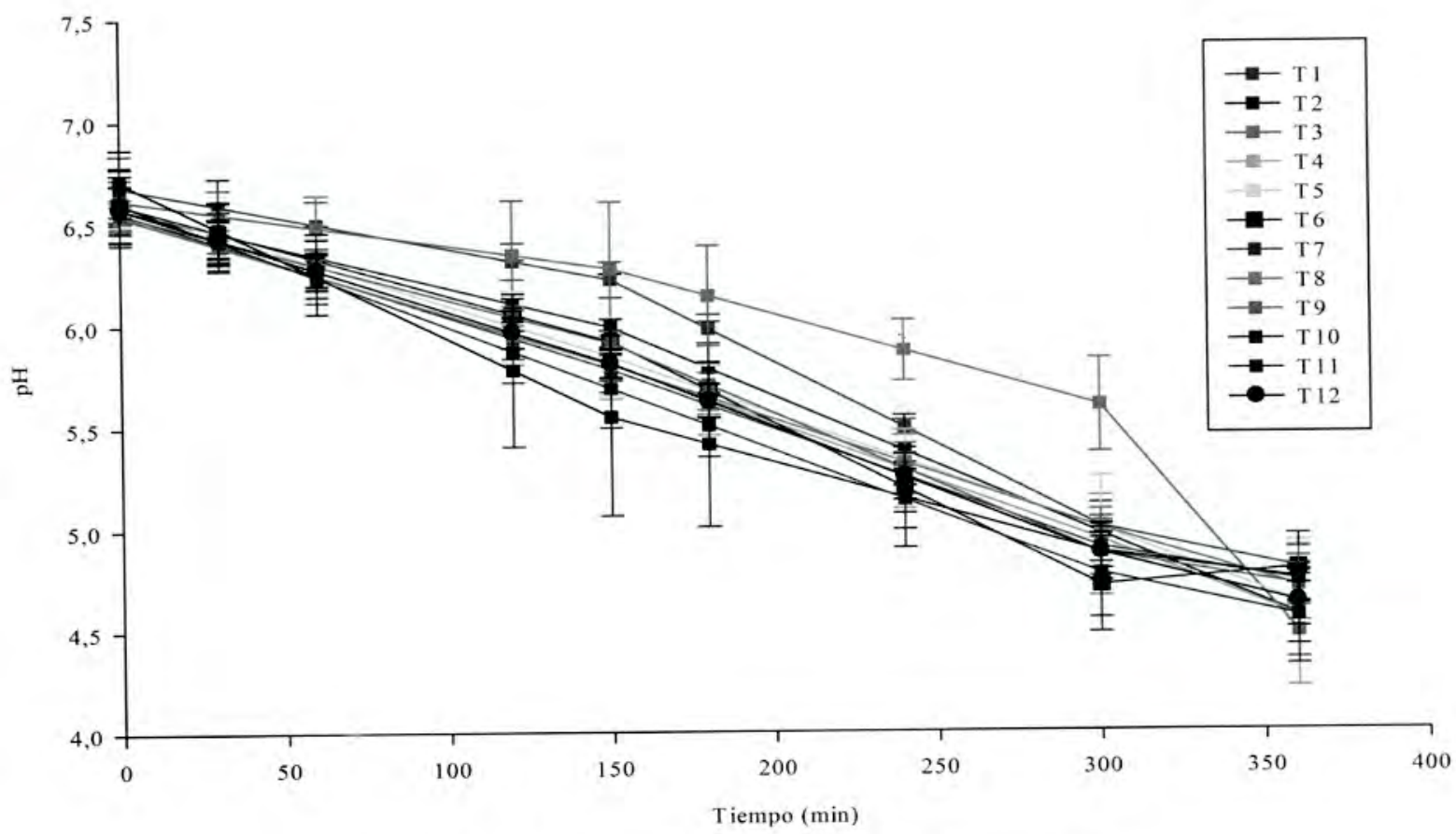

Figura $\mathrm{N}^{\circ} 01$. Descenso del $\mathrm{pH}$ para los 12 tratamientos 


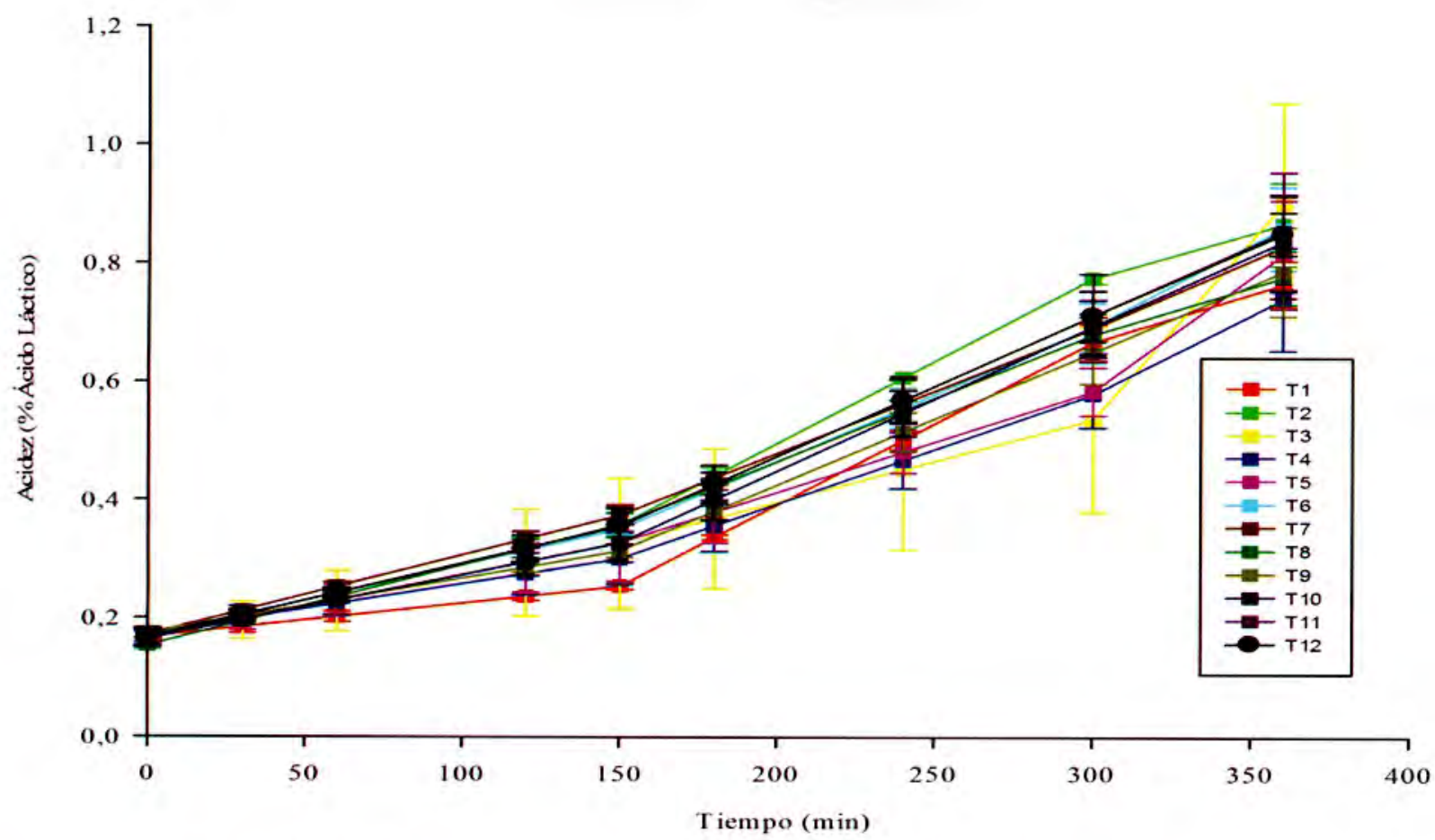

Figura $\mathrm{N}^{\circ} 02$. Desarrollo de la acidez (\% ácido láctico) para los 12 tratamientos

Tabla $\mathrm{N}^{\circ} 08$. Análisis de varianza (ANOVA) para la variación de acidez.

\begin{tabular}{lccccc}
\hline \multicolumn{1}{c}{ F. de V. } & GL & SC & CM & Fc & Significancia \\
\hline A:Temperatura & 2 & 0,00110556 & 0,000552778 & 0,07 & n.s. \\
B:Solidos Grasos & 1 & 0,0001 & 0,0001 & 0,01 & n.s. \\
C.Solidos no Grasos & 1 & 0,000177778 & 0,000177778 & 0,02 & n.s. \\
INTERACCIONES & & & & & \\
AB & 2 & 0,00845 & 0,004225 & 0,56 & n.s. \\
AC & 2 & 0,00453889 & 0,00226944 & 0,30 & n.s. \\
BC & 1 & 0,0427111 & 0,0427111 & 5,71 & $*$ \\
ABC & 2 & 0,0184389 & 0,00921944 & 1,23 & n.s. \\
Error Exp. & 24 & 0,179533 & 0,00748056 & & \\
TOTAL & 35 & 0,255056 & & & \\
\hline
\end{tabular}

La Tabla $\mathrm{N}^{\circ} 08$, muestra que la acidez es afectado por los sólidos grasos y sólidos no grasos asociadamente, al 95,0\% de confianza, efecto que observó Accolas (1977) citado por Beal et al., (1999), donde la acidez titulable es más alta en yogures fermentados entre $43^{\circ} \mathrm{C}$ y $45^{\circ} \mathrm{C}$, comparados con los fermentados a 35 y $38^{\circ} \mathrm{C}$. Sin embargo, Cho-AhYing et al., (1990), observaron que la temperatura de incubación $\left(38^{\circ} \mathrm{C}\right.$ y $\left.43^{\circ} \mathrm{C}\right)$ no afecta la acidez. Estas observaciones diferentes pueden atribuirse a la especificidad de los microorganismos usados y a la temperatura de fermentación; sin embargo Jenness y Patton (1959), citado por Valdez et al., (2005), indican que el incremento del contenido de lactosa, a través de la adición de LPD (leche en polvo descremada) se ve acompañado de un aumento de la acidez de la leche, lo cual puede conducir a una disminución del tiempo de coagulación. Esta misma teoría ha sido mantenida por Humphreys y Plunkett (1969), Haverbeck y
Jofre (1980), Tamime y Deeth (1980), Puhan (1986) y Tamime et al., (1984), citados por Valdez et al., (2005), quienes mencionan que al aumentar el nivel de sólidos totales se afecta la acidez titulable, debido a que aumenta el contenido de lactosa en la mezcla y el poder tampón (buffer) de las proteinas, fosfatos, citratos, lactatos y otros componentes de la leche.

\section{CONCLUSIONES}

Los parámetros cinćticos de crecimiento del Lactobacillus delbrueckii subsp. bulgaricus que fueron influidos por la temperatura son el tiempo de adaptación $(\lambda)$ y la velocidad máxima de crecimiento $\left(\mu_{\text {mix }}\right)$; sin embargo, la temperatura, porcentaje de grasa y sólidos no grasos no mostraron efecto alguno sobre el tiempo de generación ( $\mathrm{Tg})$.

Los parámetros cinéticos de crecimiento del Streptococcus salivarius subsp. termophilus, asi como los valores de $\mathrm{pH}$ obtenidos, no fueron influidos por la temperatura, porcentaje de grasa y sólidos no grasos.

En tanto el desarrollo de acidez (\% ácido láctico), nos permite aseverar que tanto el porcentaje de grasa y los sólidos no grasos influyen en el desarrollo de la acidez.

\section{RECOMENDACIONES}

Realizar estudios de otras bacterias acidolácticas que se encuentran en diferentes productos lácteos, utilizando otras técnicas para el conteo de colonias, teniendo en cuenta factores diferentes a la temperatura, porcentaje de grasa y sólidos no grasos.

Evaluar el desarrollo del $\mathrm{pH}$ y la velocidad de 
Chila E. et af, Influencia de la Temperatura, Porcentaje de gras y sólidos no grasus en el creeimiento cinético de bacterias acidolácticas del yogur

acidificación en relación a la cantidad de bacterias acidolácticas, en diferentes productos lácteos a diferentes porcentajes de grasa y sólidos no grasos.

\section{REFERENCIAS BIBLIOGRÁFICAS}

Accolas JP, Veaux M, Auclair J. (1971). Study of the interactions between various thermophilic and mesophilic lactic acid bacteria in relation to the manufacture of Gruyere cheese. Le lait.; 51:249

Agatangelo, D.S.E. (2007). Estudio del Comportamiento Cinético de Microorganismos de Interés en Seguridad Alimentaria con Modelos Matemáticos. Tesis Doctoral. Universidad Autónoma de Barcelona. España.

Agudelo, C.; Ortega, R. y J. L. Hoyos (2010). Determinación de parámetros cinéticos de dos inóculos lácticos: Lactobacillus plantarum A6 y bacterias ácido lácticas del yogur. Vol. 8, No2.8-16.

Aguilar, M. M. (2008). Viabilidad y propiedades fisicoquímicas de leche fermentada probiótica. Tesis de grado para optar el titulo de maestría en ciencia de alimentos. Universidad de las Américas. Puebla, México.

Alcázar, J. (1999). Diccionario Técnico de Industrias Alimentarias. Impreso en Cusco Perú.

Amiot, J. (1991). Ciencia y Tecnología de la leche. Editorial Acribia.Zaragoza España.

Bautista, E. S., R. S. Dahiya, and M. L. Speck. (1966). Identification of compounds causing symbiotic growth of Streptococcus thermophilus and Lactobacillus bulgaricus in milk. J. Dairy Res. 33:299-307.

Beal, C.; Skokanova, J.; Latrille, E.; Martin, N. y Corriev, G. (1999).Combined efects of culture conditions and storage time on acidification and viscosity of stirred yogurt. Journal Dairy Science. Vol.82, No, 4:673-681.

Belaunzarán, M. J. (2010). Desarrollo y caracterización de yogurt firme elaborado con leche ovina. Tesis para optar la licenciatura en tecnología de los alimentos. Facultad de Ciencias Veterinarias. Universidad Nacional del Centro. Buenos Aires, Tandil.

Bhunia, A., Ray, B., (2010). Fundamentos de la Microbiologia de los Alimentos. $4^{2}$. ed. México: McGrawHill Interamericana.

Bottazzi, V., Battistotti, B., and Vescovo, M. (1971). Continuous production of yoghurt cultures and stimulation of L actobacillus bulgaricus by formic acid. Milchwissenschaft.

Buchanan, R. L.; Cygnarowicz, M. L. (1990). A mathematical approach toward defining and calculating the duration of the lag phase. Food Microbiology 7:237-240.

Buchanan, R. L.; Klawitter, L. A. (1991). Effect of temperature history on the growth of Listeria monocytogenes Scott A at refrigeration temperatures. International Journal of Food Microbiology 12:235 - 246.

Castro, G.; Valbuena, E.; Sánchez, E.; Briñez, W.; Vera, H.; Leal, M. (2008). Comparación de modelos sigmoidales aplicados al crecimiento de Lactococus lactis subsp. lactis. Revista Cientifica FCV-LUZ. XVIII:pp. 582-588.

Chervaux, C., S.D. Ehrlich, and E. Maguin. (2000). Physiological study of Lactobacillus delbrueckii subsp. bulgaricus strains in a novel chemically defined medium. Applied and Environmental Microbiology, 66 (12) : 5306-531.
Cho-Ah-Ying, F.; Duitschaever, C. L. y Buteau, C. (1990). Influence of temperature of incubation on the phisicochemical and sensory quality of yoghurt. Cultures Dairy Prod. Journal.8: 11 - 14 .

Courtin, P.; Monet, V. y Rul F. (2002). Cell - wall proteinases PrtS and PrtB have a different role in Streptococcus thermophilus/Lactobacillus bulgaricus mixed cultures in milk. Microbiology, 148;3413-3421. Great Britaen.

Diaz, J.; Sosa, M. E.; Vélez, J. F. (2004). Efecto de la adición de fibra y disminución de grasa en las propiedades fisicoquímicas del yogur. Revista Mexicana de Ingeniería Química. Vol.3.287-305.

Espinoza, M. y Zapata, C. (2010). Estudio de yogur. Evaluación de calidad e información nutricional. Odecu. Chile.

Gibson, A. M.; Bratchell, N.; Roberts, A. (1988). Predicting microbial growth: growth responses of salmonellae in laboratory medium as affected by $\mathrm{pH}$, sodium chloride and storage temperature. International Journal of Food Microbiology 6:155-178.

Gibson, A.M.; Bratchell, N.; Roberts, T.A. (1987). The effect of sodium chloride and temperature on rate and extent of growth of Clostridium botulinum type $\mathrm{A}$ in pasteurized pork slurry. J. Apppl. Bacteriol. 62: 479-490.

Gómez, J. C. (1999). Tesis. Métodos de Control de Acidez en el yogur. DIA. Universidad Autónoma de Chapingo. México.

Hardi, J., y Slacanac, V. (2000). Examination of coagulation kinetics and rheological properties of fermented milk products: the influence of starter culture, milk fat content and adition of inulin. Mijekarstvo. 50(3): 217-226.

Haverbeck, J. y Jofre, H. (1980). Cultivos lácticos empleados en la industria lechera y tecnología de algunos productos lácteos fermentados. Universidad Austral de Chile. CTLValdivia - Chile. 129 paginas.

Hernández, P. (2004). Evaluación de las propiedades fisicoquímicas y reológicas del yogurt, bajo en grasa enriquecido con fibra y calcio. Tesis profesional para optar el título de Maestría en Ciencia de Alimentos. Universidad de las Américas. Puebla, México.

Humphreys, C. L. y Plunkett, M. (1969).Yoghurt: A review of its manufacture. Dairy Science Abstracts 1969 (31) 11 : 607-622. Review article $N^{\circ} .154$.

Jenness, R. y Patton, S. (1959). Principles of Dairy Chemistry.-New York. John Wiley and Sons,Inc, USA pág. 164.

Luquet, F. (1991). Leche y productos lácteos. Editorial Acribia S.A. España.

McMeekin, T.A.; J.N. Olley; T. Ross y D.A. Ratkowsky (1993). Predictive Microbiology: Theory and Application, 61-70. Research Studies Press Ltd., Tounton, Inglaterra.

Méndez, D. J. (2000). Yogurt. Instituto de Productos Lácteos. Universidad de Santiago de Compostela. España.

Meyer, I.; Marcos, R. (1982). Control de calidad de los Productos Agropecuarios. $2^{\text {a }}$ edición. Editorial trillas. España.

Montiel, L.; Delgado, C. H.; Gonzales, D. J.; Montiel, R. G., (2010). Viabilidad de cepas probióticas en leche fermentada almacenada en refrigeración. XII Congreso Nacional de Ciencia y Tecnologia de Alimentos. LA 81-LA89. 
Montville, T. J. (2000). Principios que influyen en el crecimiento, la supervivencia y la muerte microbiana en los alimentos. In: Doyle, M. P.; Beuchat, L.R.; and Montville, T. J. (2000). Microbiología de los Alimentos. Fundamentos and Fronteras. Editorial Acribia, S.A. Zaragoza (España).13 30.

Puhan, Z. (1986) Introduction In: Fermented Milk/Science and Technology-Ch. I. Bulletin IDF 227/1988.

Ray B y Bhunia A. (2010). Fundamentos de Mircrobiología de los Alimentos $4^{a}$ edición. México. Editorial McGrawHill.

Robinson, T. P.; Ocio, M. J.; Kaloti, A.; Mackey, B. M. (1998). The effect of growth environment on the lag phase of Listeria monocytogenes. International Journal of Food Microbiology 44: 83-92.

Sánchez, M. A., (1992). Tesis. Evaluación de diferentes Lactobacillus en la elaboración de un producto tipo yoghurt. FESC. UNAM. México, D.F.

Skriver, M. J., (1997). Caracterización de la textura del yogurt elaborado con diferentes concentraciones de cultivo Vicenza: IDF Simposio.

Tamime AY, Deeth HC. (1980) Yogurt: technology and biochemistry. J. Food Prot.; 43:939

Tamime, A. y Robinson, R. (1991). Yogurt Ciencia y Tecnología. Editorial Acribia, Zaragoza - España.

Tamine, A. Y., Kalab, M. y Davis, G. (1984). Microstructure of set-style yogurt manufacture from cows milk fortified by various methods. Food Microstructure, 3, 83-92.

Valdez A, J., Ludeña U., F., y Idrogo G., 2005 efecto del tiempo de almacenamiento de la leche cruda y la adición de cloruro de calcio en la viscosidad del yogurt batido. Universidad Nacional Agraria la Molina. Lima. Peru. Anales Cientificos. Vol LXI.

Veringa, H.A., Galesloot, T.E., and Davelaar, H. (1968). Symbiosis in yoghurt. II. Isolation and identification of a growth factor for Lactobacillus bulgaricus produced by Streptococcus thermophilus. Neth. Milk Dairy J.

Yousef, A. E.; Carlstrom C., (2006). Microbiología de los alimentos, manual de laboratorio. Editorial Acribia. Zaragoza, España.

Zwietering, M.H.; I. Jongenburger; F.M. Rombouts; K. Vant Riet. (1990). Modeling of the bacterial growth curve. Appl. Environ. Microbiol. 56 (6): 1875-1881.

\section{Correspondencia:}

Edwin Chila Choque: edchila@gmail.com

Thomas Ancco Vizcarra: thoanviz@gmail.com
Fecha de Recepción: 20/06/2014

Fecha de Aceptación: 02/07/2014 